\title{
Topping-off surgery vs posterior lumbar interbody fusion for degenerative lumbar disease: a finite element analysis
}

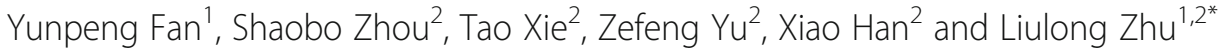

\begin{abstract}
Background: Adjacent segment disease (ASD) is a common complication after posterior lumbar interbody fusion (PLIF). Recently, a topping-off surgery (non-fusion with Coflex) has been developed to reduce the risk of ASD, yet whether and how the topping-off surgery can relieve ASD remains unclear. The purpose of this study was to explore the biomechanical effect of PLIF and Coflex on the adjacent segments via finite element (FE) analysis and discuss the efficacy of Coflex in preventing ASD.

Methods: A FE model of L3-L5 segments was generated based on the CT of a healthy volunteer via three commercially available software. Coflex and PLIF devices were modeled and implanted together with the segment model in the FE software. In the FE model, a pre-compressive load of $500 \mathrm{~N}$, equal to two-thirds of the human body mass, was applied on the top surface of the L3. In addition, four types of moments (anteflexion, rear protraction, bending, and axial rotation) set as $10 \mathrm{Nm}$ were successively applied to the FE model combined with this pre-compressive load. Then, the range of motion (ROM), the torsional rigidity, and the maximum von Mises equivalent stress on the L3-L4 intervertebral disc and the implant were analyzed.
\end{abstract}

Results: Both Coflex and PLIF reduced ROM. However, no significant difference was found in the maximum von Mises equivalent stress of adjacent segment disc between the two devices. Interestingly enough, both systems increased the torsional rigidity at the adjacent lumbar segment, and PLIF had a more significant increase. The Coflex implant had a larger maximum von Mises equivalent stress.

Conclusions: Both Coflex and PLIF reduced ROM at L3-L4, and thus improved the lumbar stability. Under the same load, both devices had almost the same maximum von Mises equivalent stress as the normal model on the adjacent intervertebral disc. But it is worthy to notice the torsional rigidity of PLIF was higher than that of Coflex, indicating that the lumbar treated with PLIF undertook a larger load to reach ROM of Coflex. Therefore, we presumed that ADS was related to a higher torsional rigidity.

Keywords: Coflex, PLIF, Adjacent segment disease, ASD, Finite element analysis

\section{Background}

Lumbar spinal stenosis (LSS), a common senile disease, has a $9.3 \%$ incidence in the elderly [1]. LSS is a major cause of surgery in people over 65 [2]. Clinical observations show the onset age of LSS is becoming younger on account of the sedentary lifestyle. LSS is clinically manifested by numbness and radiative pain in the buttocks and

\footnotetext{
* Correspondence: qq975137299@163.com

'Department of Orthopedic Surgery, The Affiliated Hangzhou Hospital of Nanjing Medical University, Hangzhou 310006, China

${ }^{2}$ The Affiliated Hangzhou First People's Hospital, Zhejiang University School of Medicine, Hangzhou 310006, China
}

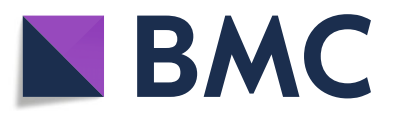

(c) The Author(s). 2019 Open Access This article is distributed under the terms of the Creative Commons Attribution 4.0 International License (http://creativecommons.org/licenses/by/4.0/), which permits unrestricted use, distribution, and reproduction in any medium, provided you give appropriate credit to the original author(s) and the source, provide a link to the Creative Commons license, and indicate if changes were made. The Creative Commons Public Domain Dedication waiver (http://creativecommons.org/publicdomain/zero/1.0/) applies to the data made available in this article, unless otherwise stated.
These symptoms exert negative impacts on the patient's physical functions. Some bedridden LSS patients even develop pneumonia and deep vein thrombosis (DVT).

Posterior lumbar interbody fusion (PLIF), as the "gold standard" in surgical practice, can significantly relieve the symptoms of nerve root compression. Although the primary segment disc compression had a low recurrence rate after PLIF, during the long-term follow-up, many patients develop LSS at an adjacent segment and recurrent relative nerve root compression. Therefore, PLIF 

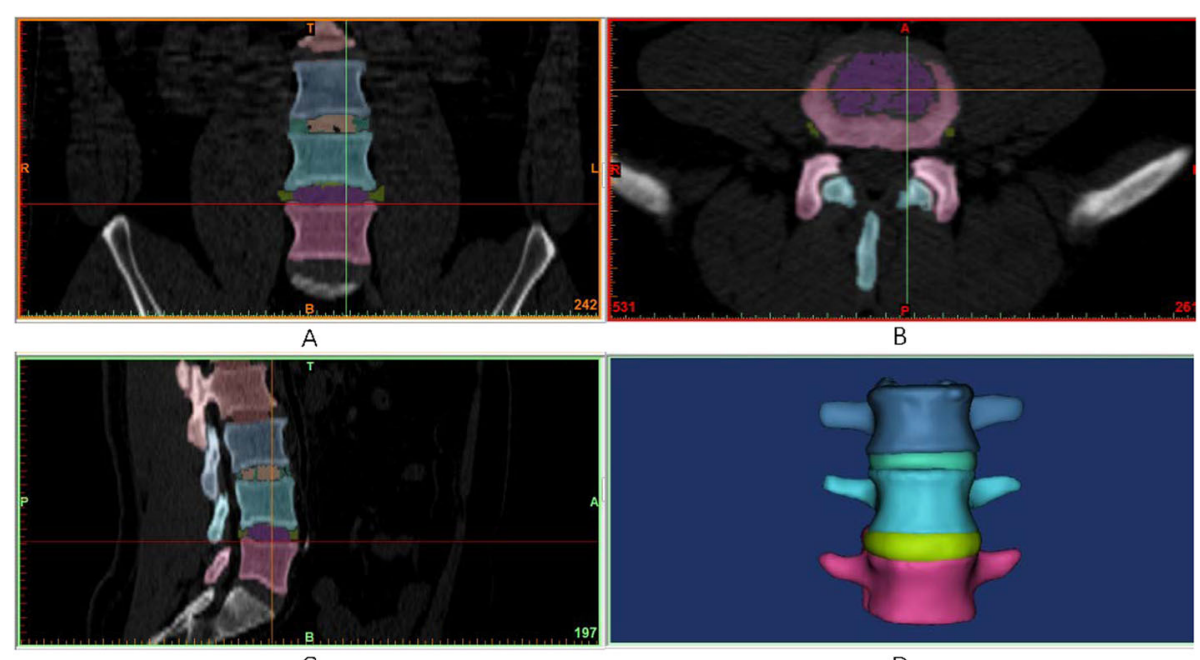

D

Fig. $1 \mathbf{a}, \mathbf{b}, \mathbf{c}$ The mask and 3D model drawing process of intervertebral disc, nucleus and vertebral body mask. $\mathbf{d}$ The mask and 3D model drawing process of $3 \mathrm{D}$ solid model
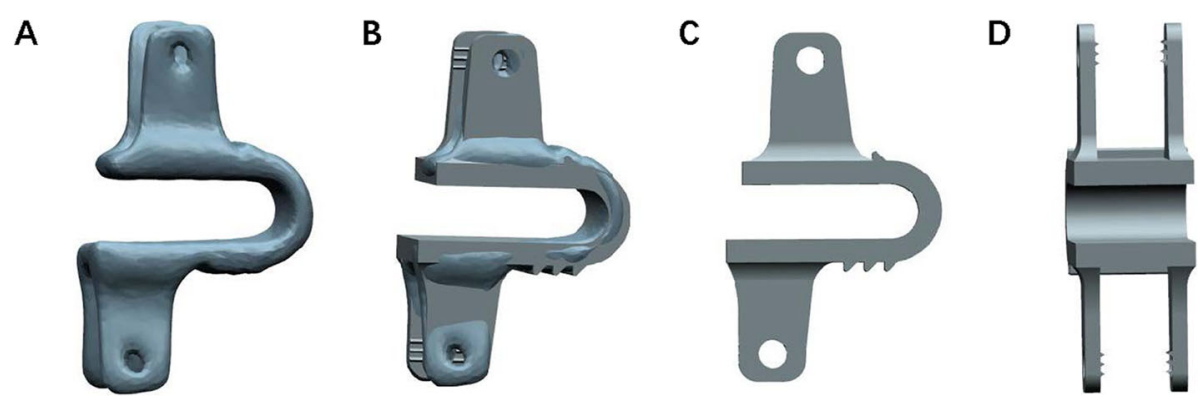

Fig. $\mathbf{2}$ a, $\mathbf{b}$ The model of the Coflex solid model. $\mathbf{c}, \mathbf{d}$ The model of the Coflex formal model

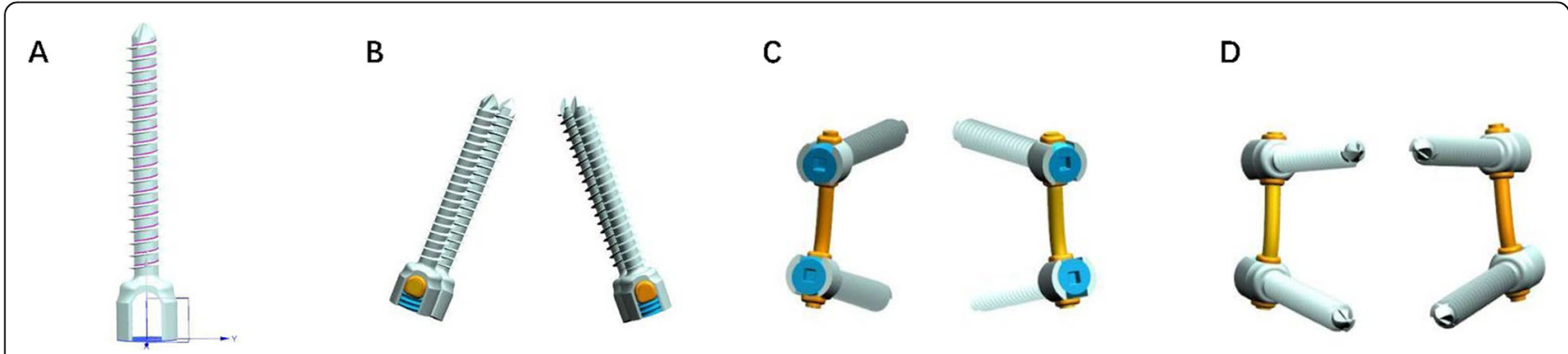

Fig. $\mathbf{3}$ a, $\mathbf{b}$ The K-ROD model of screw-rod. $\mathbf{c}$, $\mathbf{d}$ The K-ROD model 


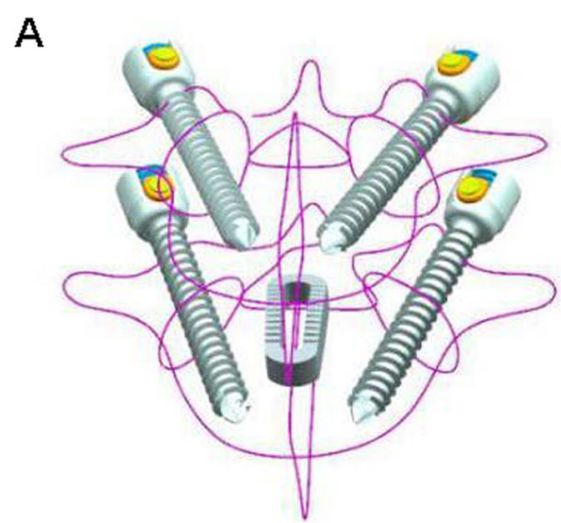

B

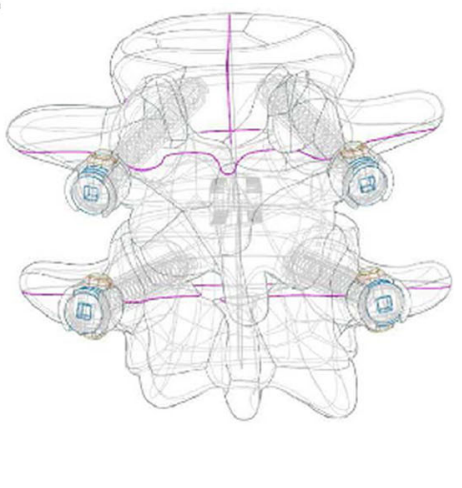

Fig. 4 a The sketch of fusion cage and K-ROD assembly model. $\mathbf{b}$ The model of fusion cage and K-ROD assembly model

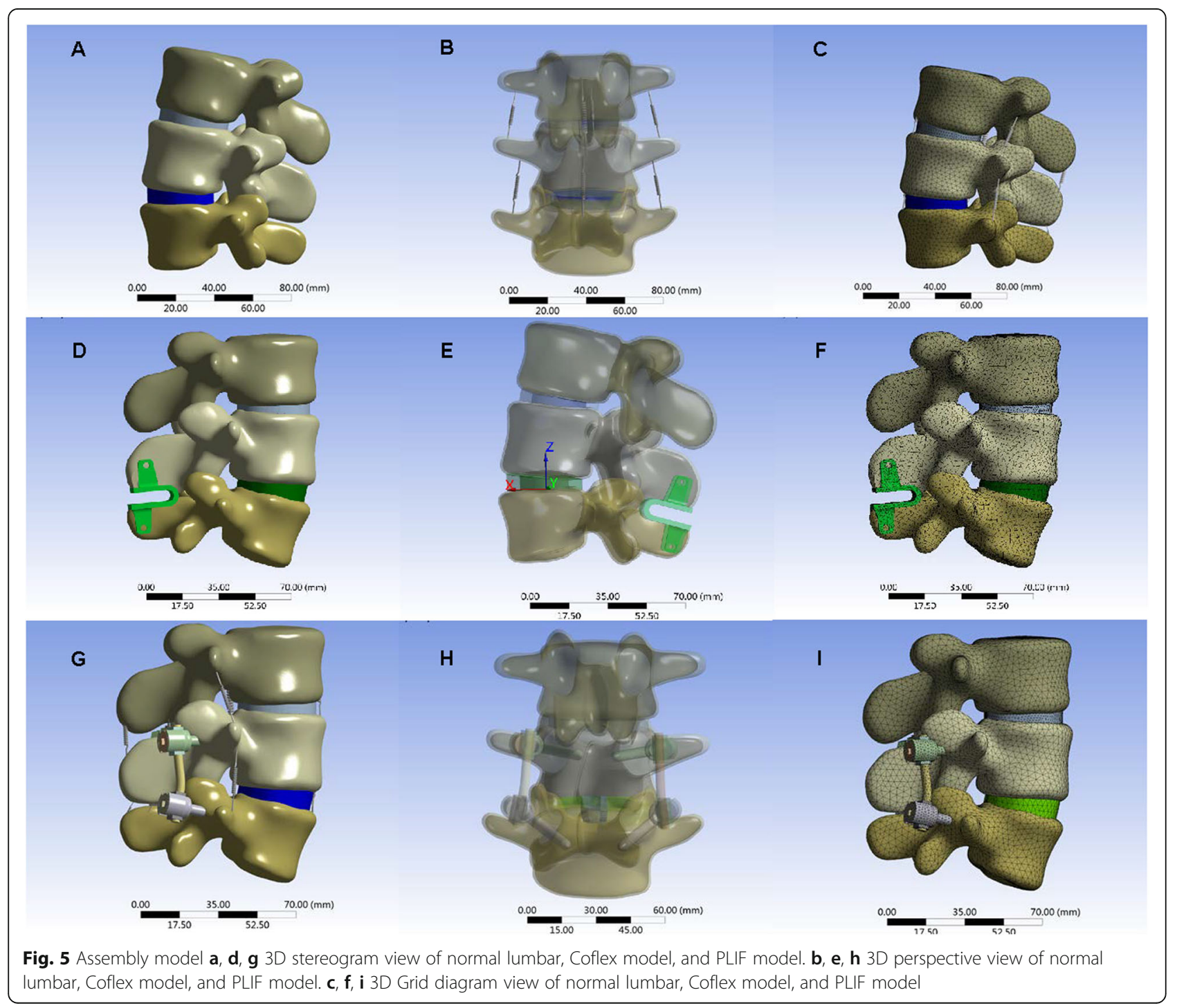


Table 1 Material properties of the tissues and implants

\begin{tabular}{llllll}
\hline & Young's modulus (MPa) & Poisson's ratio & Element type & Reference \\
\hline Cancellous bone & 150 & 0.2 & 10-node tetrahedral solid element & [1, 2] \\
Cortical bone & 18,000 & 0.3 & 10-node tetrahedral solid element & 10-node tetrahedral solid element & {$[1,2]$} \\
Nucleus pulposus & 2 & 0.45 & 0.49 & 10-node tetrahedral solid element & {$[1,3]$} \\
Annulus fibrosus & 8 & 0.3 & 10-node tetrahedral solid element & [1, 2] \\
Implant (Ti-6Al-4V) & 114,000 & 0.3 & 10-node tetrahedral solid element & {$[4,5]$} \\
Bone-cage* & 110,000 &
\end{tabular}

*Intervertebral fusion cage was used to supplement the K-ROD internal fixation system

surgery may increase the incidence of adjacent segment disease (ASD) [3, 4]. Currently, a new "topping-off" technique using Coflex, a U-shaped elastic non-fusion interspinous instrument placed between two adjacent spinous processes, is often applied in clinical practice. Some literature has demonstrated Coflex implantation can reduce the risk of ASD $[3,4]$.

Colfex has been proven safe and effective for LSS. However, the effect of the Coflex on the adjacent segment is still not clear. Lee [4] believed ASD after PLIF was caused by the compensatory increase in the mobility of the adjacent lumbar segment and the added pressure on the intervertebral disc and intervertebral joints. We presumed that torsional rigidity might be related to ASD, but the torsional rigidity was rarely addressed in the previous studies. To figure out the specific mechanism of how Coflex reduced the rate of ASD and the relationship between torsional rigidity and ASD, we conducted this study to explore the biomechanical effect between PLIF and Coflex on the adjacent segments via finite element analysis and discuss the efficacy of Coflex in preventing ASD.

\section{Methods}

\section{Establishment of basic model}

The geometrical specifications of the spine were obtained from 64 spiral CT images of a 28-year-old male without spine injury or radiographic evidence of degeneration. $\mathrm{He}$ received a SOMATOM SENSATION 64 spiral CT (Siemens, Munich, Germany) scan for health examination at our hospital. The CT images were used with his consent. The CT scans of the L3-L5 lumbar spine with Coflex or PLIF were obtained at 1-mm intervals. The threshold segmentation was used in MIMICS19 based on the CT data to obtain the masks of the intervertebral disc, nucleus pulposus, vertebral body, and the implant. Using the masks, the 3-D solid model was constructed (Fig. 1). The contour of the model was refined and the CT image distortion was decreased as much as possible. Then, the STL file was output with the quality of the mesh maintained. In GEOMAGIC12, the STL vertebral model was de-noised and smoothed with all the details maintained. All vertebral models were offset by $1 \mathrm{~mm}$ to make a smaller vertebral cancellous bone model. The STP files of all models were output and imported into UG software, and then, the final models were obtained by Boolean subtraction [5-9].

Threshold segmentation was used in MIMICS19 based on postoperative CT to obtain the Coflex implant masks. The preliminary solid model was established by 3-D model construction using the masks. The output STL file was imported into the UG software, and the Coflex model was designed based on the preliminary model using the UG software (Fig. 2).

The nailrod model and the cage model were designed and assembled using the UG software. The cage was individually designed to make the upper and lower surfaces of the cage completely match the adjacent vertebral body surfaces. The Arbeitsgemeinschaftfür Osteosynthesefragen (AO) spinal internal fixation standard was used as the reference. The screws were implanted in the center of the pedicle and a $20^{\circ}$ cohesion angle was used in the L4-L5 pedicle screws (Figs. 3 and 4).

The normal lumbar spine, Coflex, and K-ROD assembly models were imported into ANSYS 17. Then, ANSYS analysis files were generated for each model (Fig. 5). Table 1 shows the material properties of the bones, intervertebral disc, implants, and various ligaments. In ANSYS, the simulation of ligaments was achieved by adding a spring unit (tension only). Table 2 shows the properties of the spring unit [10].

\section{Pre-compressive load}

A 500-N pre-compressive load equal to two-thirds of the human body mass $(50 \mathrm{~kg}, 500 \mathrm{~N})$ [5] was applied on the

Table 2 Ligament stiffness matrix in $\mathrm{N} / \mathrm{mm}$ with the according ranges of the intervals

\begin{tabular}{|c|c|c|c|c|c|c|}
\hline Ligament & ALL & PLL & ISL & SSL & LF & IT \\
\hline L3-L4 & $39.5 \pm 20.3$ & $10.6 \pm 8.5$ & $18.1 \pm 15.9$ & $34.8 \pm 11.7$ & $34.5 \pm 6.2$ & 50.0 \\
\hline L4-L5 & $40.50 \pm 14.3$ & $25.8 \pm 15.8$ & $8.7 \pm 6.5$ & $18.0 \pm 6.9$ & $27.2 \pm 12.2$ & 50.0 \\
\hline
\end{tabular}

ALL anterior longitudinal, PLL posterior longitudinal, ISL intraspinous, SSL supra-spinous, LF flavum, IT intertransverse 


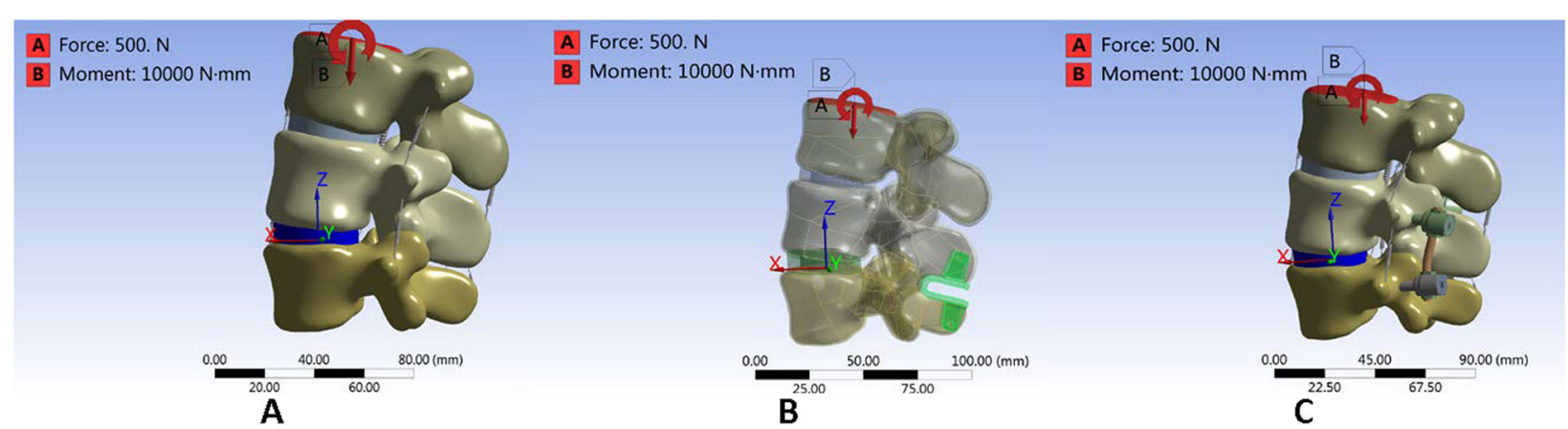

Fig. $\mathbf{6}$ Load addition method. a Load addition method model in normal model. b Load addition method model in Coflex model. c Load addition method model in PLIF model

upper surface of the L3 lumbar vertebra. An additional moment of $10 \mathrm{~N} * \mathrm{~m}(10,000 \mathrm{~N} * \mathrm{~mm})$ was exerted in each direction as described in the literature [5-12] to simulate lumbar anteflexion, rear protraction, and rotation (Fig. 6).

\section{Simplified restriction}

A six-degree-of-freedom rigidly fixed constraint was applied on the lower surface of the L5 lumbar vertebra according to the previous literature $[11,12]$ to verify that the lower surface of L5 vertebral would not produce displacement and rotation when moment was added.

\section{Bind}

All ligaments were simplified into spring units as shown in Table 2. The BOND connection was used between the vertebral body and the intervertebral disc. The facet joint surface was subjected to frictional simulation and the friction coefficient was set as 0.2 [4-9, 11-13]. "No Separation" was used to connect the surfaces of Coflex with those of the spinous processes. The BOND connection was applied in all the K-ROD components, cage, and vertebral body connections.

\section{Meshing}

To ensure the comparability of the models and prompt calculation, and also to avoid the calculation error caused by meshing, a 10-node tetrahedral mesh was used in mesh 7. A more refined mesh of $1.5 \mathrm{~mm}$ was used in L3/4 intervertebral disc and the inner implant. The octahedral mesh was used in the cancellous bone. The same meshing method was applied in the normal lumbar, Coflex, and PLIF implant models. The mesh of $3 \mathrm{~mm}$ was used in all the other parts. The meshing was performed using the ANSYS software (ANSYS WORKBENCH 15.0). The units used are shown in Table 1. No warnings and failures were reported. Table 3 shows the number of nodes and elements in the three models.

\section{Verification method}

Verification of L4, L5 segment axial compression (displacement-load curve)

After establishing the L4/L5 lumbar model, a precompressive load ranging from 500 to $2000 \mathrm{~N}$ was applied on the upper surface of L4. The axial displacement of the lumbar vertebral model was calculated and compared with the references [14-18], as shown in Fig. 7.

\section{Measurement of lumbar range of motion and torsional rigidity}

The origin of the local coordinate system was defined as the center of endplate in the distal vertebral body. Perpendicular to the endplate in the sagittal position was the $X$-axis. Parallel to the endplate was the $Z$-axis (right) and the $Y$-axis (left).

With the distal vertebral body fixed, two nodes on the upper surface of the adjacent lumbar were selected. The coordinates of the two nodes before precompressive load application were $(X 1, Y 1, Z 1),(X 2$, $Y 2, Z 2)$. The coordinates of the two nodes after precompressive load application were $(X 3, Y 3, Z 3),(X 4$, $Y 4, Z 4)$. The lines connecting the two points before and after pre-compressive load application formed the angle $\theta$ (i.e., the maximum angular displacement) [11, 19-21]. The formula is presented as follows:

$$
\begin{aligned}
\theta= & \frac{180}{\pi} \\
& \times \operatorname{acrcos} \frac{\left(X_{1}-X_{2}\right) \times\left(X_{3}-X_{4}\right)+\left(Y_{1}-Y_{2}\right) \times\left(Y_{3}=Y_{4}\right)+\left(Z_{1}-Z_{2}\right) \times\left(Z_{3}-Z_{4}\right)}{\sqrt{\left(X_{1}-X_{2}\right)^{2}+\left(Y_{1}-Y_{2}\right)^{2}+\left(Z_{1}-Z_{2}\right)^{2} \times \sqrt{\left(X_{3}-X_{4}\right)^{2}+\left(Y_{3}-Y_{4}\right)^{2}+\left(Z_{3}-Z_{4}\right)^{2}}}}
\end{aligned}
$$

Table 3 Number of nodes and elements in the models

\begin{tabular}{lll}
\hline Model & Nodes & Elements \\
\hline Normal & 201654 & 136934 \\
Coflex & 211836 & 142718 \\
K-ROD & 345475 & 235081 \\
\hline
\end{tabular}




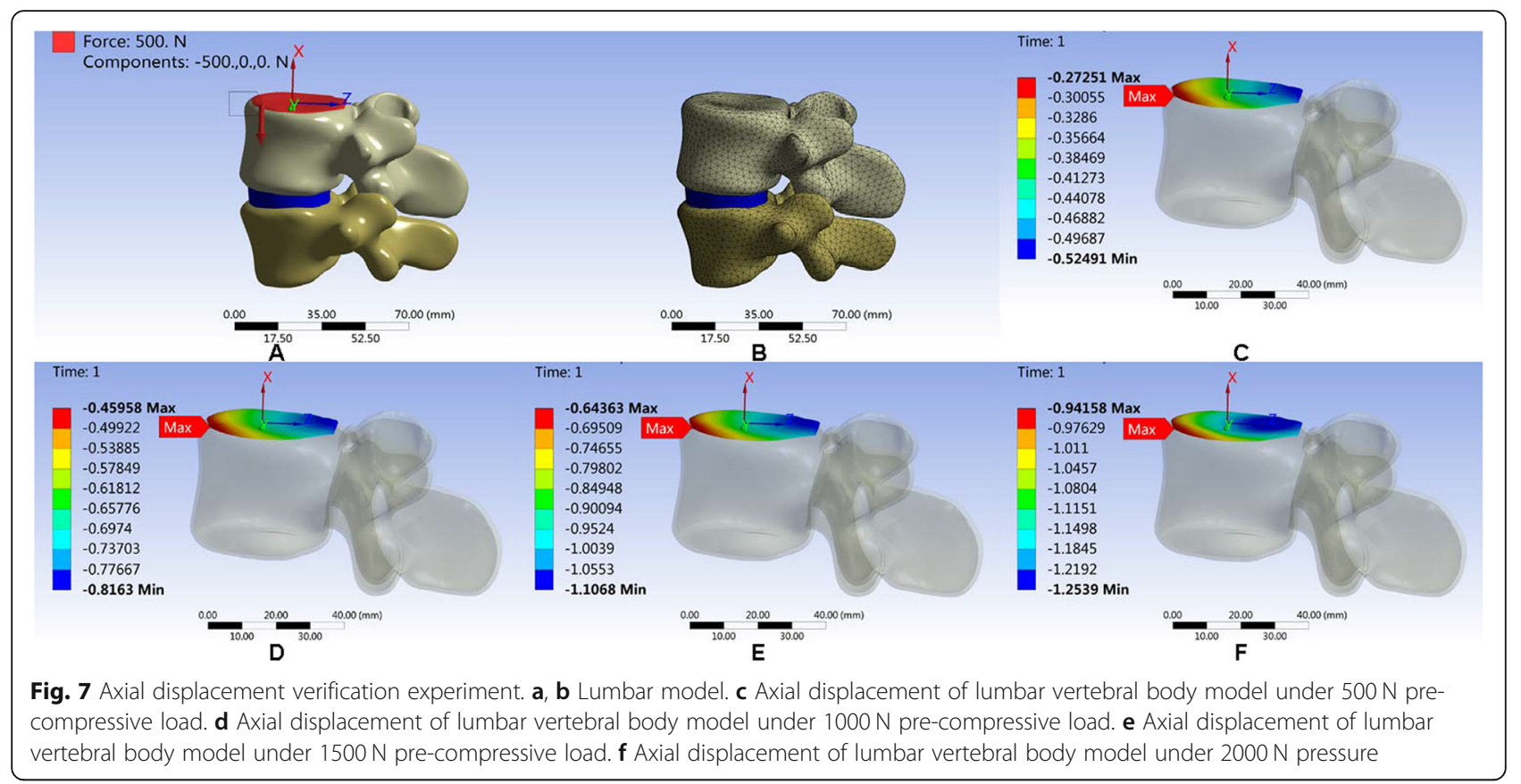

Torsional rigidity was the moment required to produce a unit torsion of the lumbar vertebra and it was measured using the following formula: Torsional rigidi$\operatorname{ty}(k)=M / \theta, \quad(M$ : the exerted moment; $\theta$ :the range of motion).

\section{Verification of maximum von Mises equivalent stress on} L3/L4 intervertebral disc

The uppermost L3 was not subject to any constraints. An evenly distributed $500-\mathrm{N}$ pre-compressive load was exerted on the endplate of the L3 vertebral body; the

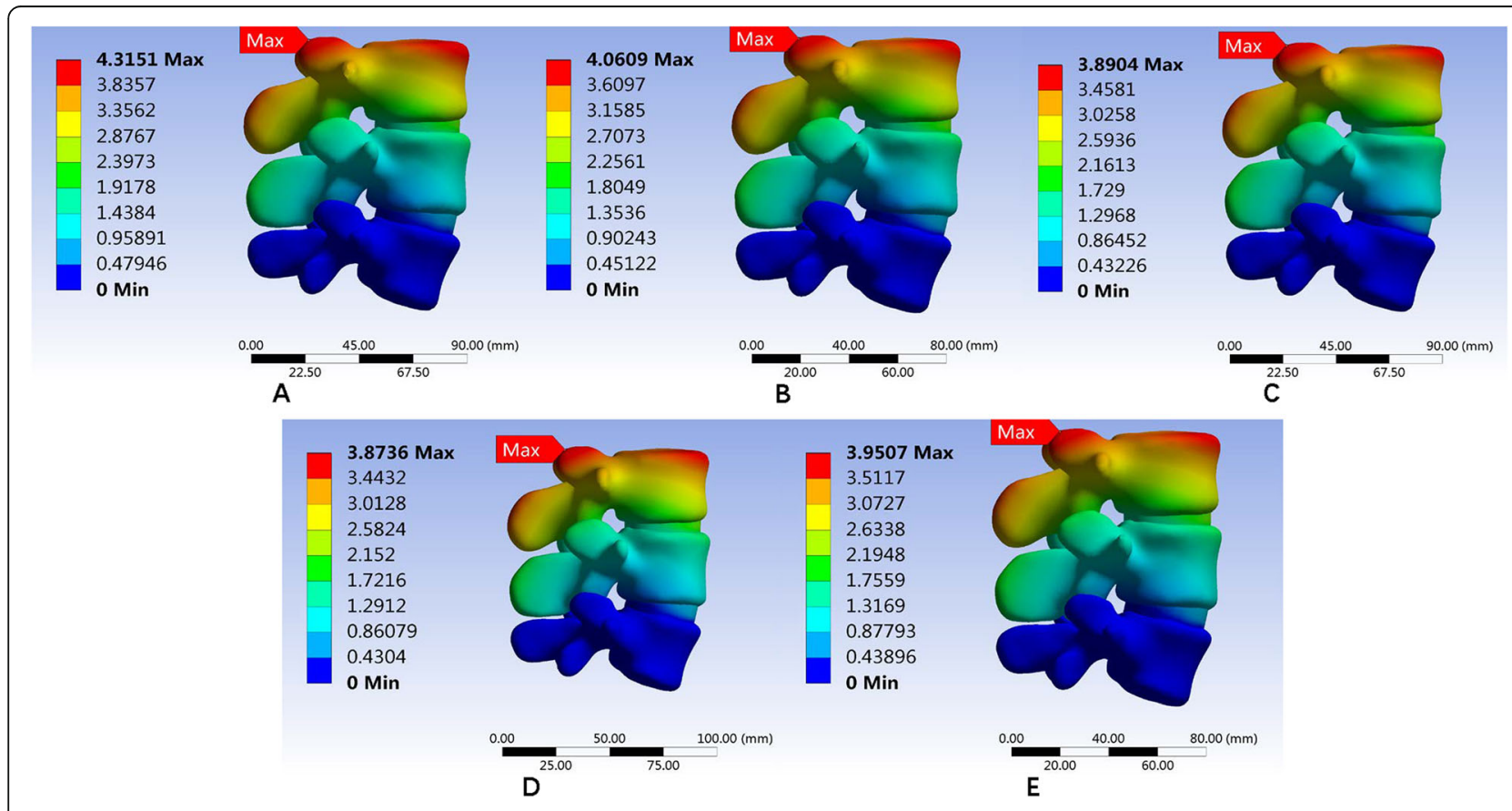

Fig. 8 Evaluation of the sensitivity of the elements. a Low-medium. b Medium. c Medium-high. d Optimized. e High densities 
Table 4 The sensitivity of the elements

\begin{tabular}{llllll}
\hline Mesh & Nodes & Element & Approximate computational time $(\mathrm{min})$ & Max model displacement $(\mathrm{mm})$ & Adjacent disc von Mises (MPa) \\
\hline Coarse & 125970 & 84676 & 8 & 4.3151 & 1.734 \\
Medium & 181156 & 123871 & 15 & 4.0609 & 1.455 \\
Fine & 537548 & 375680 & 40 & 3.8904 & 1.8582 \\
Very fine & 942449 & 675635 & 180 & 3.8736 & 1.8219 \\
Optimize & 201654 & 136934 & 25 & 3.9507 & 1.8162 \\
\hline
\end{tabular}

motor moment was $10 \mathrm{Nm}[8,19,20]$. The maximum von Mises equivalent stress on the L3/L4 intervertebral disc was calculated by FE analysis and compared with the references.

\section{Evaluation of the sensitivity of the elements}

The low-medium, medium, medium-high, optimized, and high densities of five representative meshes were performed to determine the number of elements (Fig. 8). An analysis was performed using the five densities, and the results were converged from the medium- to highmesh densities. Table 4 shows the number of elements, number of nodes, computational time, max model displacement, and equivalent stress on the adjacent disc for each density.

\section{Results}

Verification of experimental results

Verification of L4, L5 segment axial compression

(displacement-load curve)

Compared with the results from the literature [14-18], ours was approximated to that of Virgin's [18], and between those of Virgin's and Markolf's. The axial compression stiffness of our model was of an intermediate level among the results in the literature. The curve was obviously nonlinear, which was in accordance with the literature (Fig. 9).

\section{Measurement of lumbar ROM and torsional rigidity}

The ROM and torsional rigidity of this study is shown in Table 5. The ROM and torsional rigidity of the models were in good accordance with those reported in the literature, as shown in Table 6.

\section{Verification of maximum von Mises equivalent stress on L3/L4 intervertebral disc}

The maximum von Mises equivalent stress on the L3L4 intervertebral disc in this model was in accordance with those from the other literature (Table 7 ).

\section{Evaluation of the sensitivity of the elements}

For high and medium-high mesh, the convergence and accuracy were increased; however, they were not practiced on account of the increased computational

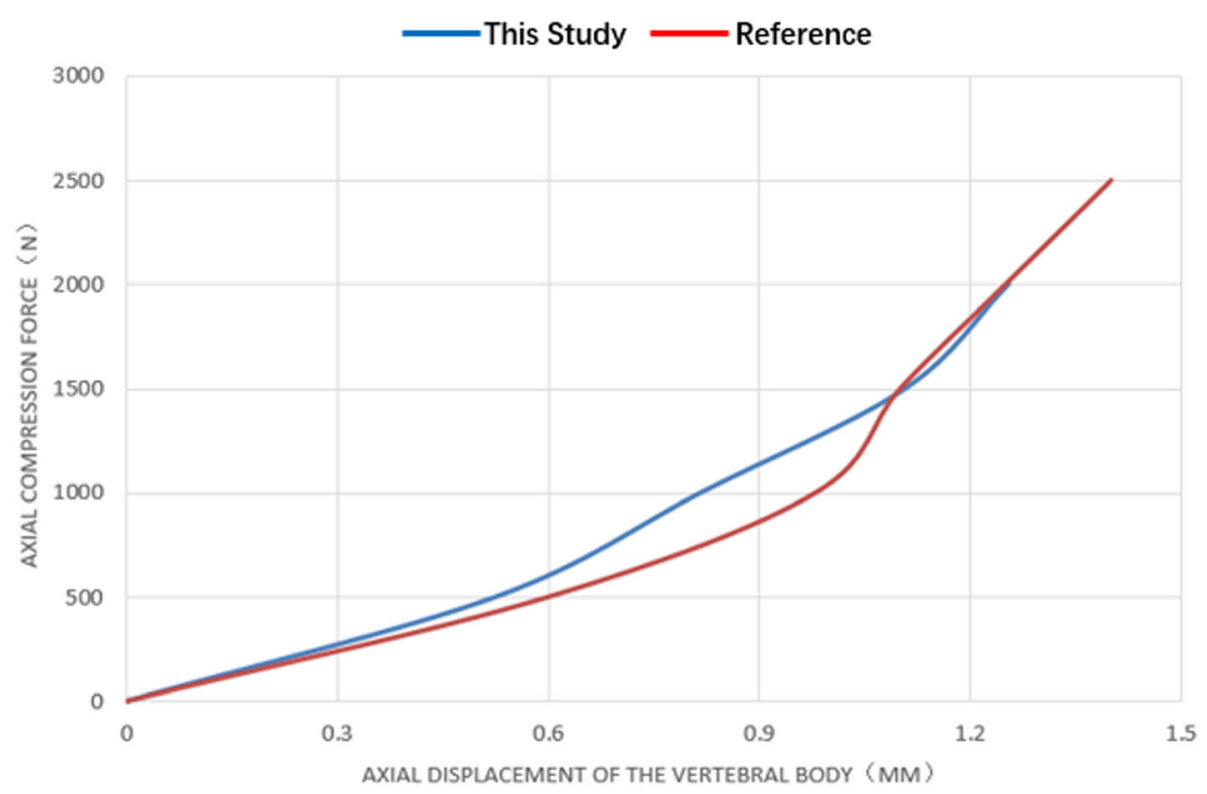

Fig. 9 Displacement-load comparison curve between this study and reference 
Table 5 ROM and torsional rigidity in different motions of this study

\begin{tabular}{|c|c|c|c|c|c|}
\hline Motion state & Vertebral & $\begin{array}{l}\mathrm{ROM} \\
\left({ }^{\circ}\right)\end{array}$ & $\begin{array}{l}\text { Average ROM of } L 3 \text { and } L 4 \\
\left({ }^{\circ}\right)\end{array}$ & $\begin{array}{l}\text { Rotational stiffness (N.m/ } \\
\text { o) }\end{array}$ & $\begin{array}{l}\text { Average rotational stiffness of } L 3 \text { and } L 4 \\
\left(\mathrm{~N} . \mathrm{m} /{ }^{\circ}\right)\end{array}$ \\
\hline \multirow[t]{2}{*}{ Anteflexion 10(N*m) } & L3 & 4.8739 & 3.4137 & 2.051745 & 3.585381 \\
\hline & $\llcorner 4$ & 1.9535 & & 5.119017 & \\
\hline \multirow{2}{*}{$\begin{array}{l}\text { Rear protraction } \\
10\left(\mathrm{~N}^{*} \mathrm{~m}\right)\end{array}$} & L3 & 5.1141 & 3.88215 & 1.955378 & 2.864339 \\
\hline & $\llcorner 4$ & 2.6502 & & 3.7733 & \\
\hline \multirow{2}{*}{$\begin{array}{l}\text { Lateral bending } \\
10\left(N^{*} \mathrm{~m}\right)\end{array}$} & L3 & 3.65885 & 3.037475 & 3.65885 & 3.450752 \\
\hline & $\llcorner 4$ & 2.4161 & & 2.4161 & \\
\hline \multirow[t]{2}{*}{ Axial rotation $10\left(\mathrm{~N}^{*} \mathrm{~m}\right)$} & L3 & 4.68015 & 3.50455 & 4.68015 & 3.312286 \\
\hline & $\llcorner 4$ & 2.32895 & & 2.32895 & \\
\hline
\end{tabular}

Table 6 Comparison of ROM and torsional rigidity $\left(\mathrm{N} . \mathrm{m} /{ }^{\circ}\right)$

\begin{tabular}{lllllll}
\hline & Load moment $\left(\mathrm{N}^{*} \mathrm{~m}\right)$ & Anteflexion & Rear protraction & Lateral bending & Axial rotation & Average \\
\hline JiaW Zhi & 10 & 2.35 & 3.58 & 2.86 & 2.5 & 8.98 \\
DeS Zhang & 10 & 1.62 & 3.03 & 2.226875 \\
Vadapalli S & 10 & 2.32 & 2.85 & 2.53 & 3.45 & 3.64 \\
YuF Huang & 10 & 1.83 & 2.92 & 3.51 & 3.66 & 3.3122857 \\
This study & 10 & 3.585381 & 2.864339 & 3.450752 & 3.329299 \\
\hline
\end{tabular}

Table 7 von Mises stress in the intervertebral disc of L3-L4 comparison with other literatures (Mpa)

\begin{tabular}{lllllll}
\hline & Load moment $\left(\mathrm{N}^{*} \mathrm{~m}\right)$ & Upright & Anteflexion & Rear protraction & Lateral bending & Axial rotation \\
\hline ZhaoH Chen & 10 & - & 1.951 & 3.037 & 1.916 & 1.831 \\
Wang X & 10 & - & 3.03 & 4.95 & 1.52 & 2.11 \\
El Reich M & 10 & 0.994 & 2.15 & 3.04 & 1.86 & 3.76 \\
YuF Huang & 10 & 0.978 & 2.92 & 2.329 & 1.917 & 2.405 \\
This study & 10 & 1.2671 & 1.8162 & 2.943 & 2.6322 & 2.1069 \\
\hline
\end{tabular}

Table 8 Analysis of the state and influence on the interpretation by densities of the mesh

\begin{tabular}{|c|c|c|c|c|c|}
\hline Mesh & $\begin{array}{l}\text { Number of } \\
\text { nodes }\end{array}$ & $\begin{array}{l}\text { Number of } \\
\text { elements }\end{array}$ & $\begin{array}{l}\text { Approximate computational time } \\
\text { (min) }\end{array}$ & $\begin{array}{l}\text { Max model displacement } \\
(\mathrm{mm})\end{array}$ & $\begin{array}{l}\text { Stress on adjacent disc } \\
\text { (Mpa) }\end{array}$ \\
\hline $\begin{array}{l}\text { Low- } \\
\text { medium }\end{array}$ & 125970 & 84676 & 8 & 4.3151 & 1.734 \\
\hline Medium & 181156 & 123871 & 15 & 4.0609 & 1.455 \\
\hline $\begin{array}{l}\text { Medium- } \\
\text { high }\end{array}$ & 537548 & 375680 & 40 & 3.8904 & 1.8582 \\
\hline High & 942449 & 675635 & 180 & 3.8736 & 1.8219 \\
\hline Optimization & 201654 & 136934 & 25 & 3.9507 & 1.8162 \\
\hline
\end{tabular}




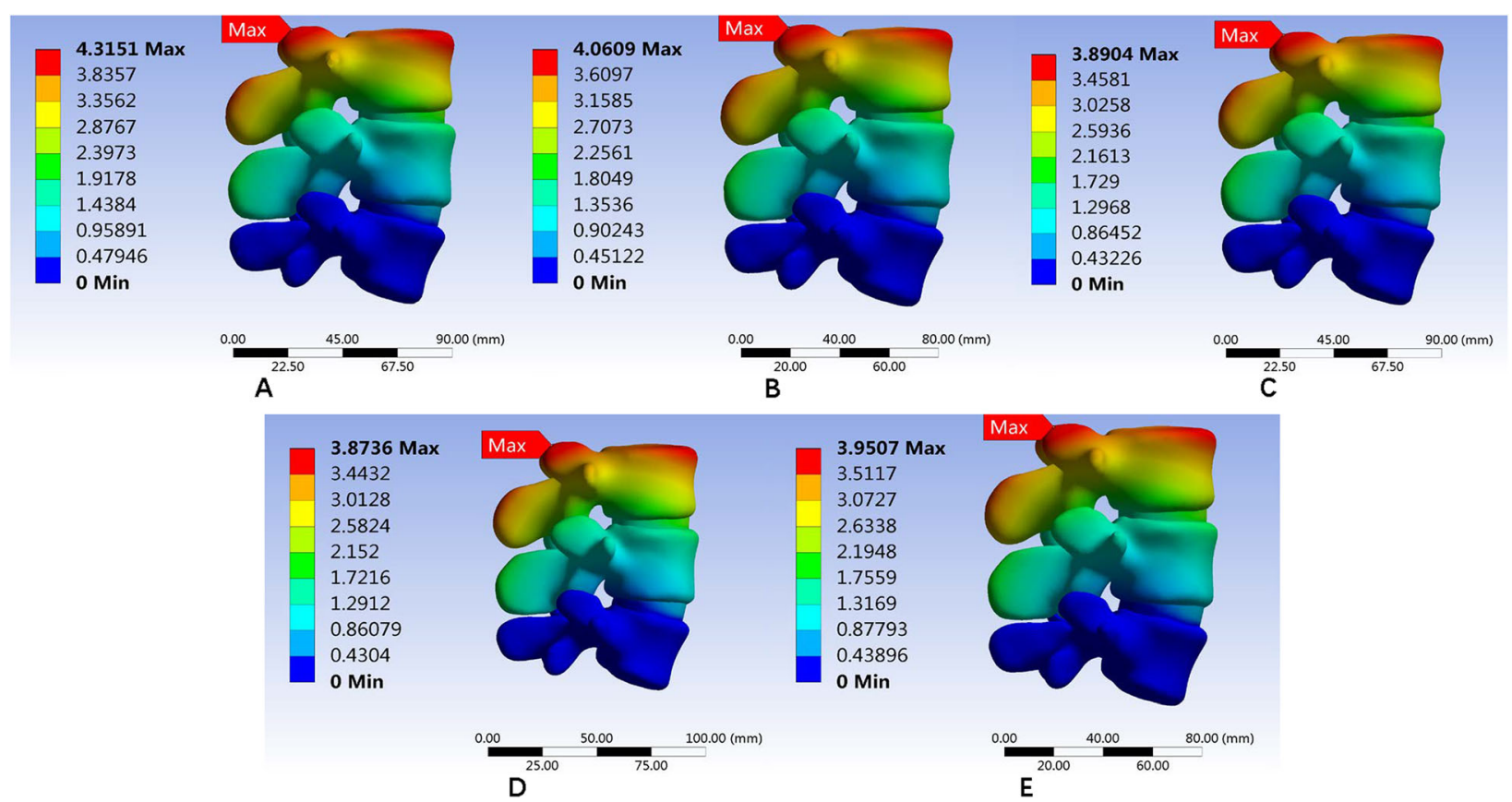

Fig. 10 Classification according to the mesh densities to evaluate the sensitivity of the elements. a Coarse mesh. b Medium mesh. c Fine mesh. d Very fine mesh. e optimized mesh

time. Therefore, the optimized mesh with a high degree of convergence was selected for the analysis (Table 8, Fig. 10).

\section{L3-L4 lumbar ROM and torsional rigidity}

In the normal model, the lumbar ROM of the L3-L4 was higher than the others. The Coflex and PLIF models exhibited significant differences in anteflexion, rear protraction, and right lateral bending. The Coflex model had a significantly smaller L3-L4 axial rotation angle than the normal model, and the rotation in the upright position had the smallest ROM. The right axial rotation showed the largest ROM. However, the ROMs of upright, rear protraction, and left lateral bending showed no significant change compared with the PLIF model. In the PLIF model, the upright position had the smallest L3-L4 ROM and the biggest right axial rotation. The ROM of PLIF showed significant reductions, but the left lateral bending did not change significantly, compared with the normal and Coflex models (Table 9).
In terms of the L3-L4 lumbar spine torsional rigidity, the PLIF model was significantly higher than the normal and Coflex models, and the Coflex model was higher than the normal. In the normal model, the rear protraction had the smallest stiffness and the left lateral bending had the largest stiffness. In the Coflex model, the stiffness of L3-L4 right axial rotation was the smallest and the right lateral bending rotation was the largest; compared with the normal, the stiffness of anteflexion, rear protraction, left lateral bending, and left axial rotation was significantly increased. The average L3-L4 lumbar torsional rigidity reached $3.708858 \mathrm{N*} \mathrm{m} /{ }^{\circ}$, which was significantly larger than the normal model. In the PLIF model, compared with Coflex, L3-L4 lumbar torsional rigidity was significantly increased in all the positions except in rear protraction and right lateral bending. All the data are presented in Table 10.

\section{Maximum von Mises equivalent stress on $L 3 / L 4$ intervertebral disc}

The maximum von Mises equivalent stress on L3-L4 intervertebral disc showed no significant difference

Table 9 Finite element analysis of L3-L4 lumbar ROM $\left(^{\circ}\right)$

\begin{tabular}{llllllll}
\hline & Upright & Anteflexion & Rear protraction & Right lateral bending & Left lateral bending & Left axial rotation & Right axial rotation \\
\hline Normal & 1.8073 & 4.8739 & 5.1141 & 3.9043 & 3.4134 & 4.6831 & 4.6772 \\
Coflex & 1.1788 & 2.6823 & 2.1049 & 1.6505 & 3.1443 & 4.1651 & 4.6857 \\
PLIF & 1.0288 & 1.1214 & 2.1049 & 2.0873 & 3.1128 & 2.7848 & 3.287 \\
\hline
\end{tabular}


Table $10 \mathrm{~L} 3-\left\llcorner 4\right.$ lumbar torsional rigidity $\left(\mathrm{N}^{*} \mathrm{~m} /{ }^{\circ}\right)$

\begin{tabular}{llllllll}
\hline & Anteflexion & Rear protraction & Right lateral bending & Left lateral bending & Left axial rotation & Right axial rotation & Average \\
\hline Normal & 2.051745 & 1.955378 & 2.561279 & 2.92963 & 2.135338 & 2.138031 & 2.295234 \\
Coflex & 3.728144 & 4.75082 & 6.05877 & 3.180358 & 2.400903 & 2.134153 & 3.708858 \\
K-ROD & 8.917425 & 4.75082 & 4.790878 & 3.212542 & 3.590922 & 3.042288 & 4.717479 \\
\hline
\end{tabular}

among the three models. In the normal model, the intervertebral disc had the largest maximum von Mises equivalent stress when in the right lateral bending position. The smallest stress appeared when in the upright position. The maximum von Mises equivalent stresses in all positions were smaller than the other two models (Fig. 11). In the Coflex group, the maximum von Mises equivalent stress of the intervertebral disc was the largest in right lateral bending and the smallest in the upright position (Fig. 12). The maximum von Mises equivalent stress of L3-L4 intervertebral disc in the PLIF model did not differ significantly from that of the Coflex model (Fig. 13). All the data are presented in Table 11.

\section{Maximum von Mises equivalent stress of implant}

In this study, we performed the finite element analysis of Coflex, cage, and nail rods in each model to measure the maximum von Mises equivalent stress of the implant. It showed that Coflex had the smallest maximum von Mises equivalent stress when in the upright position, and the smallest maximum von Mises equivalent stress appeared in the right axial rotation. The maximum von Mises equivalent stress of the cage was the smallest compared with the other two parts, and the smallest stress appeared in the upright position and the largest in right axial rotation. The smallest stress on the nail was in anteflexion, unlike the other two implants. The largest stress was at the right lateral bending (Figs. 14, 15, and 16). All data are presented in Table 12 .

\section{Discussion}

PLIF surgery, the "the golden standard" for severe LSS, can significantly relieve LSS symptoms (e.g., radical pain and palsy), but it can also accelerate the degeneration of the adjacent segment. Paul Park [21] reported a high incidence of ASD after PLIF surgery. According to two other studies, the incidence even reached 100\% [22]. Shinya Okuda [22] reported a case of repeated ASD after PLIF in which the patient underwent four operations at different adjacent lumbar segments. Although the patient's symptoms were resolved by the operation, the time between surgeries was increasingly shorter and the sacral slope decreased.

The "topping-off" surgical method-using either a hybrid stabilization device (HSD) or an inter-spinous process device (IPD) - is being widely used to treat ASD. Khoueir et al. [23] have classified posterior dynamic

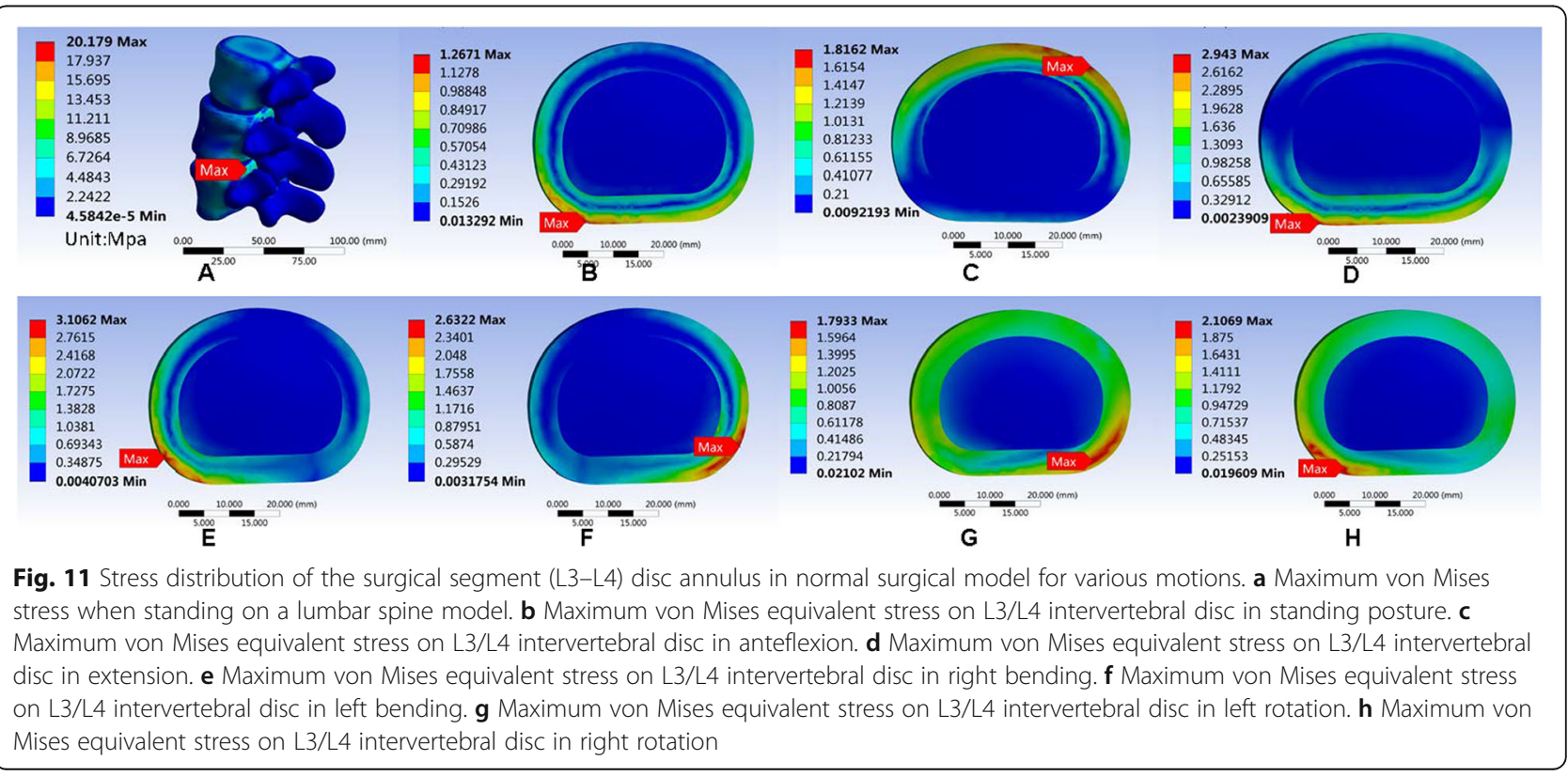




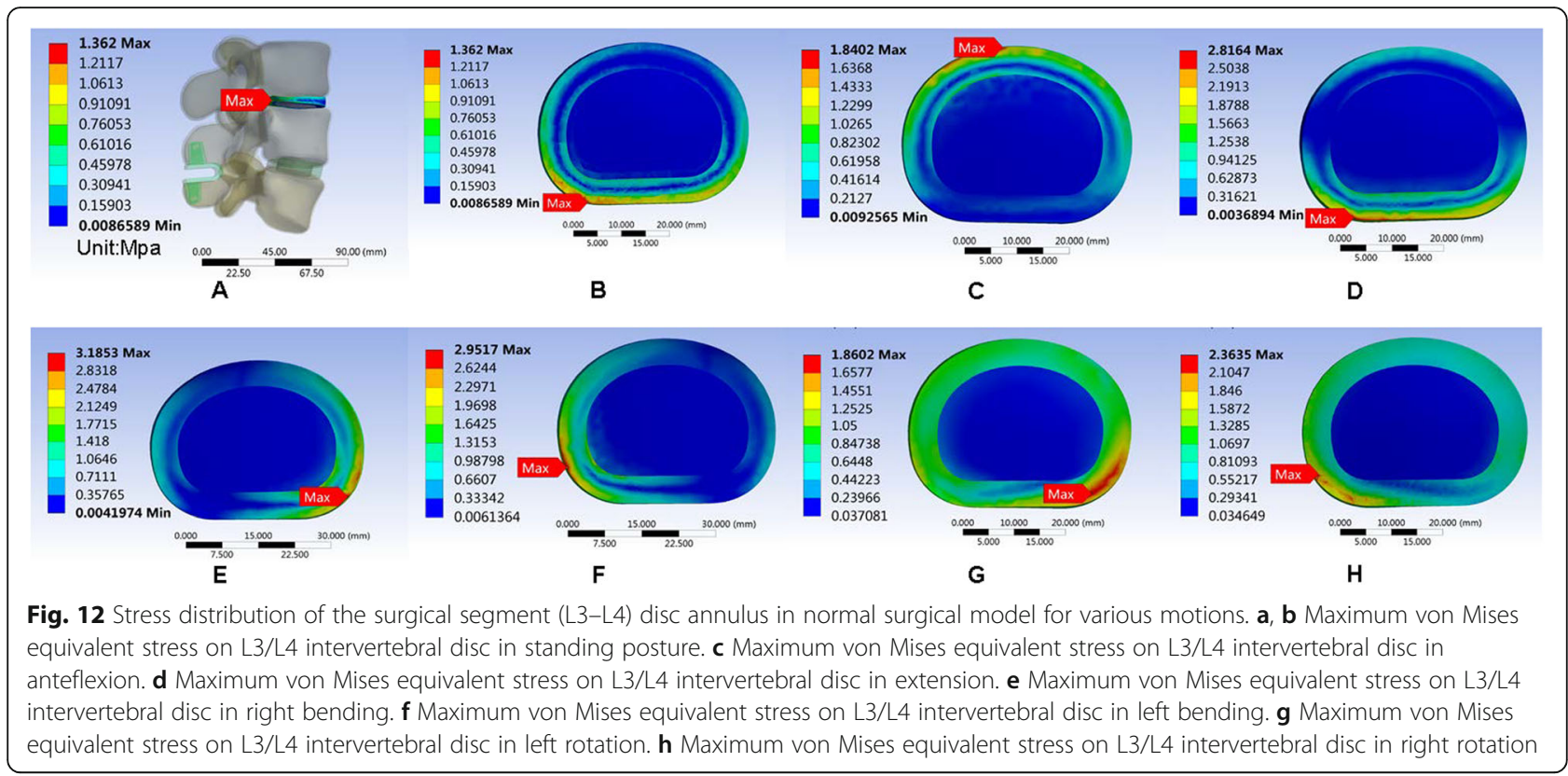

stabilization devices into three categories: (1) HSD with pedicle screw/rod instrument; (2) IPD such as Wallis and Coflex; (3) total facet replacement system. The device placed at the default adjacent segment after PLIF can effectively reduce the ROM and loading force on the adjacent segment. The systematic review by Po-Hsin Chou [24] showed that the fusion-alone group had a higher incidence of radiographic ASD (52.6\%) and symptomatic ASD (11.6\%) than revision surgery group (8.1\%). Besides, the HSD and fusion groups had a higher incidence of radiographic ASD at the supra-adjacent segment ( $10.5 \%$ and $24.7 \%$, respectively) than the IPD (1\%). In a review of 91 cases, Lu et al. [25] evaluated and compared the incidence of ASD in the PLIF and the "topping-off" (an IPD was put at the adjacent segment proximal to the PLIF instrument) groups, showing that radiographic ASD occurred in 20 cases $(48 \%)$ in the PLIF group and 3 (6\%) in the "topping-off" group. The PLIF group had 9 symptomatic cases while only 3 were found in the "topping-off" group. He concluded that the "topping-off" device reduced the risk of ASD. Both PLIF and Wallis relieved the LSS symptoms [25]. In addition,

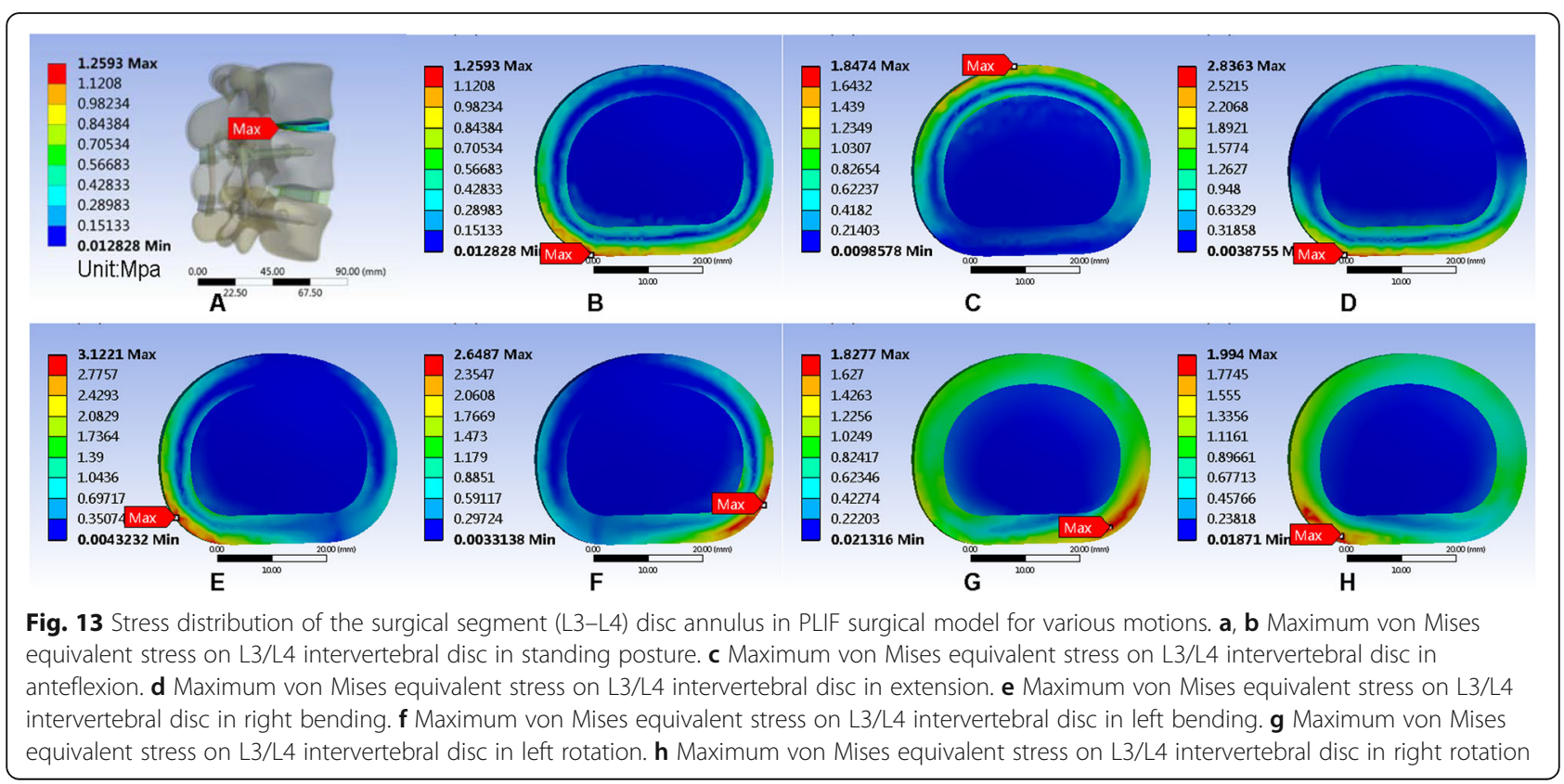


Table 11 Maximum von Mises equivalent stress (Mpa) of $L 3 / L 4$ intervertebral disc

\begin{tabular}{llllllll}
\hline & Upright & Anteflexion & Rear protraction & Right lateral bending & Left lateral bending & Left axial rotation & Right axial rotation \\
\hline Normal & 1.2671 & 1.8162 & 2.943 & 3.1062 & 2.6322 & 1.7933 & 2.1069 \\
Coflex & 1.362 & 1.8402 & 2.8164 & 3.1853 & 2.9517 & 1.8602 & 2.3635 \\
K-ROD & 1.2593 & 1.8474 & 2.8363 & 3.1221 & 2.6487 & 1.8277 & 1.994 \\
\hline
\end{tabular}

Wallis significantly reduced the adjacent segment degeneration.

Coflex is an inter-spinous fixation device for the "topping-off" technology. It is an elastic U-shaped structure implanted after possessing the inter-spinous and supraspinous ligaments. Qu SD [26] believed that Coflex relieved the nerve root compression by propping up the spinous process, maintaining the lordosis of the implanted segment, and reducing the ligamentum flavum invasion of the spinal canal. The distraction force also enlarged the intervertebral foramen and reduced the load on the intervertebral disc and the facet joint in flexion. The meta-analysis by $\mathrm{Li}$ et al. [27] showed that Coflex was more effective than PLIF in terms of decompression, the Oswestry Disability Index (ODI), length of hospital stay (LOS), and blood loss. Yuan et al. [28] held that Coflex surgery had significantly less blood loss, shorter hospital stay, and operative time than PLIF $(p<$ 0.001), and it also had a lower reoperation rate for ASD than PLIF, yet with no statistical difference $(11.1 \%$ vs. $4.8 \%, p=0.277$ ). He also thought Coflex was not suitable for the patients with lumbar disc herniation.

To investigate the mechanism of Coflex in reducing ASD incidence, mechanical analysis of the supra-lumbar segment is needed. Finite element analysis can simulate real physical systems (geometry and load cases) and perform the measurement using a mathematical approximation program. With simple and mutual elements, a finite unknown quantity can approximate a real system of infinitely unknown quantity.

In this study, no significant difference of intervertebral disc load force on the adjacent segment was found between Coflex and PLIF under a $500-\mathrm{N}$ pre-compressive load. The increased adjacent disc pressure of Coflex ranged from -5 to $10 \%$, while the pressure of PLIF ranged from -10 to $2 \%$, indicating that the higher load force on the adjacent disc was not a primary risk factor of ASD.

Coflex significantly reduced the anteflexion and rear protraction $\mathrm{ROM}$ of the adjacent segment, and the lateral bending was also decreased. No change was found in the angle of axial rotation. By comparison, PLIF reduced the ROM in all motions. The decreased ROM promoted lumbar stability in both Coflex and PLIF models. Two factors might contribute to the difference in Coflex activity between our results and those from the literature: first, ours was an idealized model and the micro-motion of the Coflex facet was smaller than the

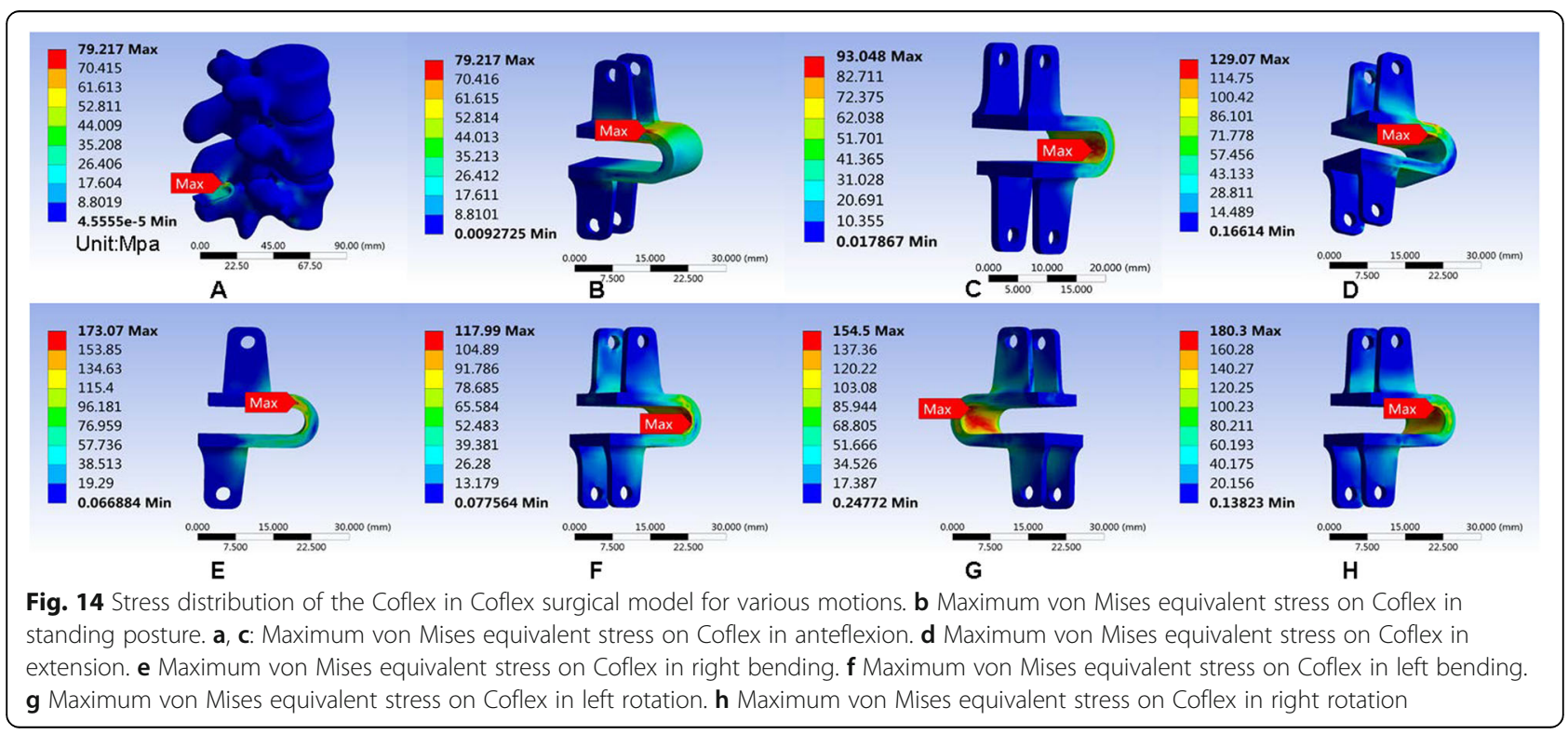




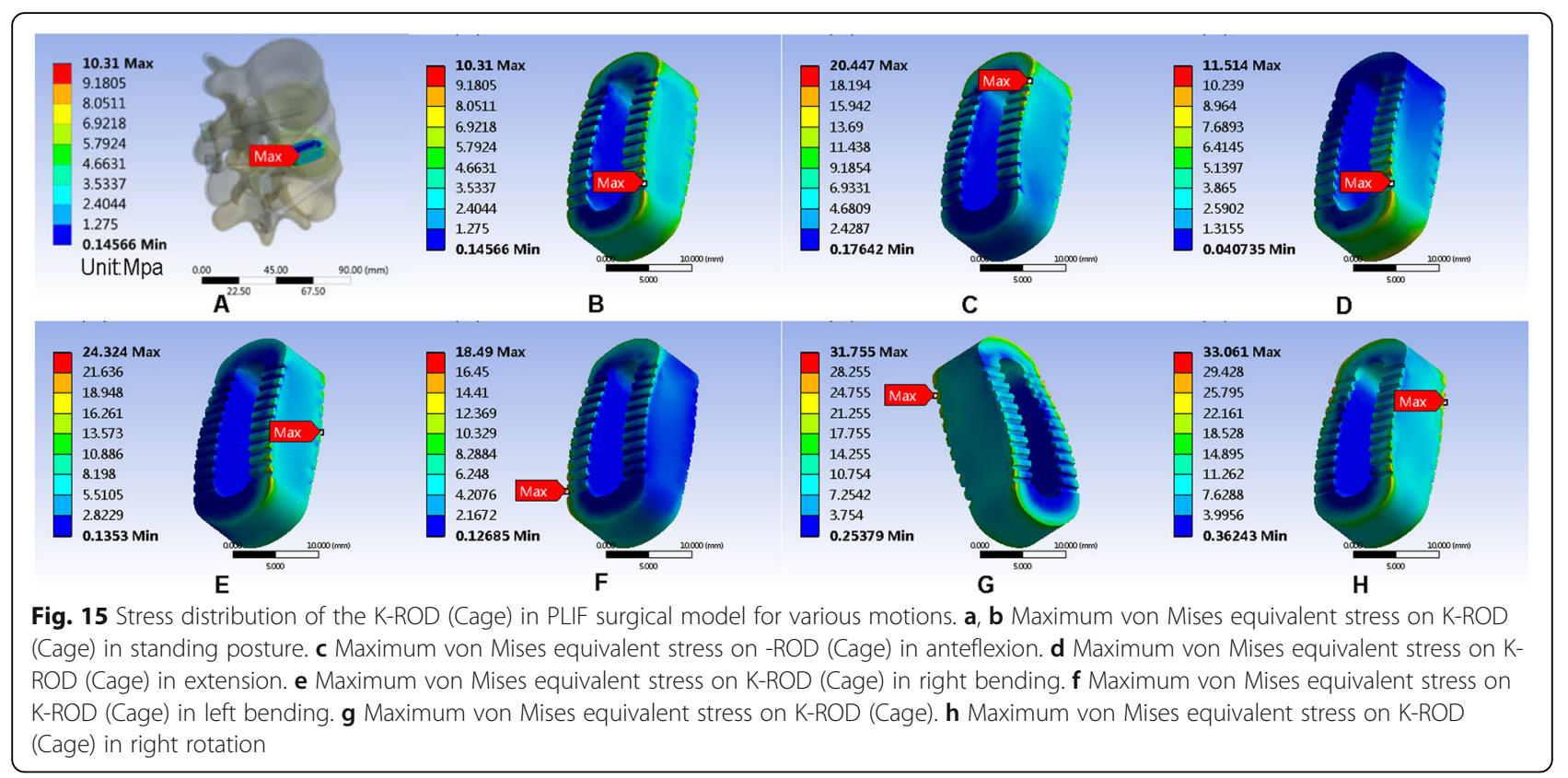

actual one; second, the intervertebral facet joint in our model was intact, unlike those in the literature, which were partially resected.

The increased torsional rigidity can impose a heavier burden on the adjacent segment. PLIF increases the torsional rigidity, which means the patient may have a higher load burden on the adjacent disc and facet joint in rotational activity. The higher load burden would then lead to degeneration of the adjacent intervertebral segments and the nucleus pulposus would be prone to protrusion and nerve root compression.
As a result, the patients receiving PLIF would have a higher incidence of ADS and suffer from nerve root compression. Hence, higher torsional rigidity could be a primary risk factor of ASD.

Rigorous conclusions cannot be made based on the results of this study because of the small sample size and the limited number of working conditions for each finite element model. A larger sample size and more working conditions should be included in the further study. The maximum von Mises equivalent stress on the intervertebral disc needs to be statistically analyzed and compared.

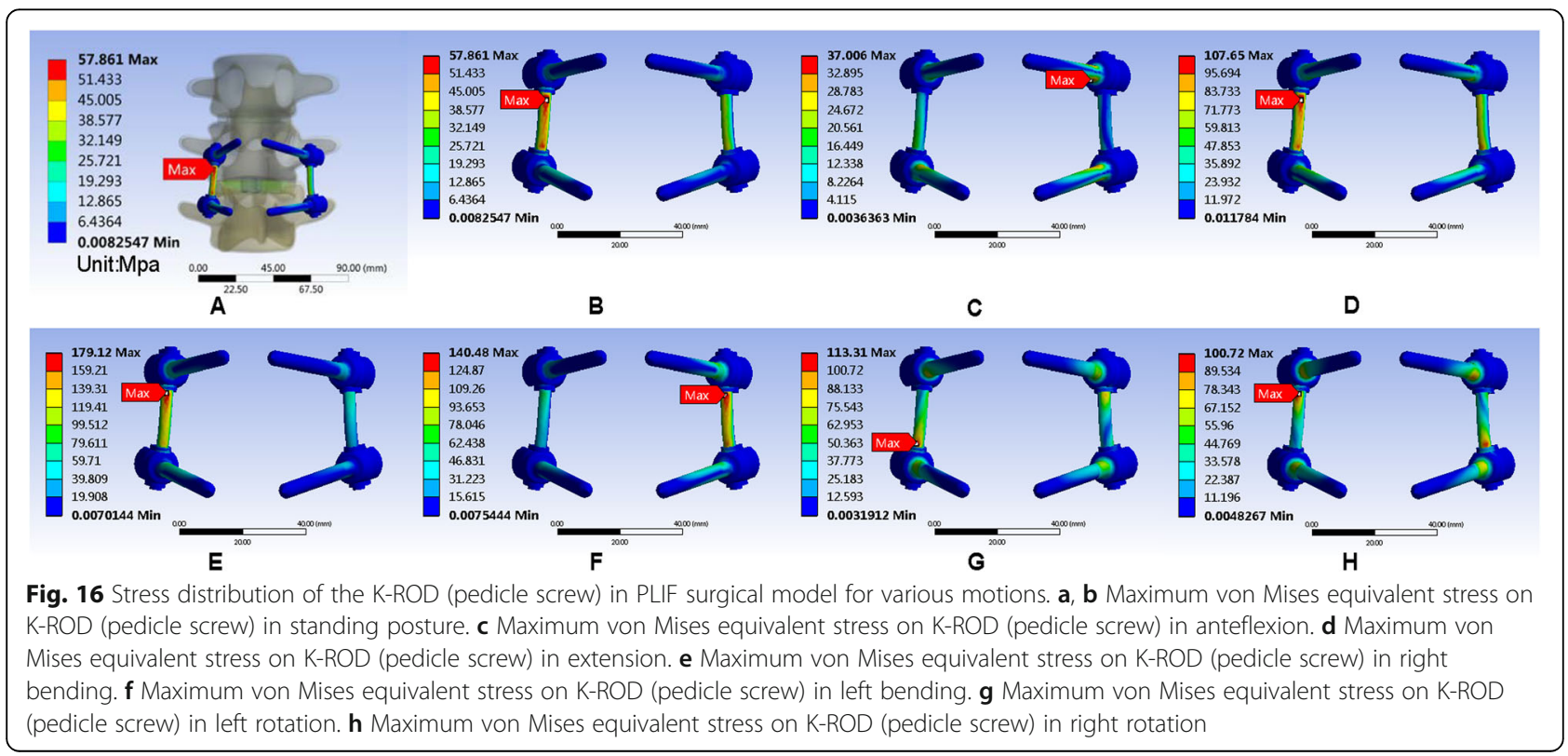


Table 12 Maximum von Mises equivalent stress (Mpa) of implants

\begin{tabular}{llllllll}
\hline & Upright & Anteflexion & Rear protraction & Right lateral bending & Left lateral bending & Left axial rotation & Right axial rotation \\
\hline Coflex & 79.217 & 93.048 & 129.07 & 173.07 & 117.99 & 154.5 & 180.3 \\
Cage & 10.31 & 20.447 & 11.514 & 24.324 & 18.49 & 31.755 & 33.061 \\
Screw-rod & 57.861 & 37.006 & 107.65 & 179.12 & 140.48 & 113.31 & 100.72 \\
\hline
\end{tabular}

A comprehensive comparison of the effects of Coflex and PLIF on adjacent segments is also necessary in the future study.

\section{Conclusion}

Both Coflex and PLIF reduced lumbar ROM and therefore provided stability at the surgical and adjacent segments. Under the same pressure, both devices had almost the same maximum von Mises stress as the normal model on the adjacent intervertebral disc. But it is worthy to notice that the torsional rigidity of both PLIF and Coflex models was higher than that of the normal model, and PLIF produced an even higher burden on the adjacent segment than Coflex. It indicates that the lumbar vertebra of patient treated with PLIF undertakes a larger load to reach ROM of Coflex. Therefore, we presumed that ADS was related to higher torsional rigidity.

\section{Abbreviations}

AO: Arbeitsgemeinschaftfür Osteosynthesefragen; ASD: Adjacent segment disease; DVT: Deep vein thrombosis; FE: Finite element; HSD: Hybrid stabilization device; IPD: Inter-spinous process device; LOS: Length of hospital stay; LSS: Lumbar spinal stenosis; ODI: Oswestry Disability Index; PLIF: Posterior lumbar interbody fusion

\section{Acknowledgements}

We thank Nanjing medical University library system for all of the help and resources and our deepest gratitude goes to the anonymous reviewers and editors for their careful work and thoughtful suggestions that have helped improve this paper substantially.

\section{Authors' contributions}

YF conceived and designed the study and wrote this manuscript. SZ searched database and reviewed studies. TX and ZY performed data analysis and prepare the initial draft of the manuscript. $L Z$ and $X H$ participated in interpretation of data, helped in drafting the manuscript and critically reviewed the manuscript. All authors read and approved the final manuscript.

\section{Funding}

This research was supported by Zhejiang Provincial Natural Science Foundation of China (Grant No.: LQ17H060001), Medical and Health Science and Technology Project of Zhejiang Province (Grant No.: 2019326687), Medical Health Science and Technology Project of Hangzhou City (Grant No: 20170533B38) and Zhejiang province natural science Foundation of China (Grant No.: LQ17H160012.)

\section{Availability of data and materials}

The datasets used and/or analyzed during the current study are available from the corresponding author on reasonable request.

Ethics approval and consent to participate Not applicable.

\section{Consent for publication}

Not applicable.

\section{Competing interests}

The authors declare that they have no competing interests.

Received: 10 September 2019 Accepted: 28 November 2019

Published online: 30 December 2019

\section{References}

1. Ishimoto Y, Yoshimura N, Muraki S, et al. Prevalence of symptomatic lumbar spinal stenosis and its association with physical performance in a population-based cohort in Japan: the Wakayama Spine Study. Osteoarthritis Cartilage. 2012;20(10):1103-8.

2. Deyo RA, Mirza SK, Martin Bl, et al. Trends, major medical complications, and charges associated with surgery for lumbar spinal stenosis in older adults. JAMA. 2010;303:1259-65.

3. Zaina F, Tomkins-Lane C, Carragee $E$, et al. Surgical versus non-surgical treatment for lumbar spinal stenosis. Cochrane Database Syst Rev. 2016; 1(14):CD010264.

4. Lee N, Shin DA, Kim KN, et al. Paradoxical radiographic changes of Coflex Interspinous device with minimum 2-year follow-up in lumbar spinal stenosis. World Neurosurg. 2016;85:177-84.

5. Ming $\mathrm{CZ}_{\text {, Song } M H}$, Jie $Z$, et al. Three-dimensional finite element analyses of unilateral pedicles crews fixation in lumbar spine. Chin J Spine Spinal Cord. 2010;20(8):684688.

6. Yang M, Zeng C, Li L, et al. Establishment of 3D-finite element model for analysis of biomechanical stability of extraforaminal or transforaminal lumbar interbody fusion. J Tongji Univ Med Sci. 2018;39(3):41-7.

7. Yang M, Zeng C, Li L, et al. Biomechanical analyses of extraforaminal lumbar interbody fusion [J]. J Tongji Univ Med Sci. 2018;39(4):51-5.

8. Jia-zhi Y, Wu Z-h, Wang X-s, et al. Finite element analysis on stress change of lumbar spine. Natl Med J China. 2009;89(17):1162-5.

9. Hao J, Piao Z, Li J, et al. Establishment of a normal human lumbar threedimensional finite element model based on CT image and reverse engineering methods. J Clin Rehabilitative Tissue Eng Res. 2012;16(4):593-6.

10. Putzer M, Auer S, Malpica W, et al. A numerical study to determine the effect of ligament stiffness on kinematics of the lumbar spine during flexion. BMC Musculoskelet Disord. 2016;17(1):95.

11. Shin JK, Lim BY, Goh TS, et al. Effect of the screw type (S2-alar-iliac and iliac), screw length, and screw head angle on the risk of screw and adjacent bone failures after a spinopelvic fixation technique: a finite element analysis. PLoS One. 2018;13(8):e0201801

12. Zhao Y, Li J, Wang D, Liu Y, Tan J, Zhang S. Comparison of stability of two kinds of sacro-iliac screws in the fixation of bilateral sacral fractures in a finite element model. Injury. 2012;43(4):490-4.

13. Driscoll M, Aubin C-E, Moreau A, Parent S. Biomechanical comparison of fusionless growth modulation corrective techniques in pediatric scoliosis. Med Biol Eng Comput. 2011;49(12):1437-45.

14. Schultz AB, Warwich DN, Berkson MH, et al. Mechanical properties of human lumbar spine motion segments-Part I: responses in flexion,extension,lateral bending, and torsion. J Biomech Eng. 1979;101:46.

15. Andersson GB, Schultz AB. Effects of fluid injection on mechanical properties of intervertebral discs. J Biomech. 1979;12:453.

16. Tencer AF, Ahmed AM, Burke DL. Some static mechanical properties of the lumbar intervertebral joint, intact and injured. J Biomech Eng. 1982;104(3):193.

17. Wilke HJ, Neef $P$, Caimi $M$, et al. New in vivo measurements of pressures in the intervertebral disc in daily life. Spine. 1999;24(8):755.

18. Virgin WJ. Experimental investigations into the physical properties of the intervertebral disc. J Bone Joint Surg Br. 1951;33-B(4):607. 
19. Huang $Y$, et al. Establishment of normal lumbosacral vertebral threedimensional finite element. Orthop Biomech Mater Clin Study. 2015;15(5):16.

20. Vadapalli S, Sairyo K, Goel VK, et al. Biomechanical rationale for using polyetheretherketone (PEEK) spacers for lumbar interbody fusion:a finite element study. Spine. 2006;31(26):E992-8.

21. Park P, Garton HJ, Gala VC, et al. Adjacent segment disease after lumbar or lumbosacral fusion: review of the literature. Spine. 2004;29(17):1938-44.

22. Okuda S, Oda T, Yamasaki R, et al. Repeated adjacent-segment degeneration after posterior lumbar interbody fusion. J Neurosurg Spine. 2014;20(5):538-41.

23. Khoueir P, Kim KA, Wang MY. Classification of posterior dynamic stabilization devices. Neurosurgical Focus. 2007;22:E3.

24. Po-Hsin C, Hsi-Hsien L, An HS, et al. Could the topping-off technique be the preventive strategy against adjacent segment disease after pedicle screwbased fusion in lumbar degenerative diseases? A systematic review. Biomed Res Int. 2017;2017:1-13.

25. Lu K, Liliang PC, Wang HK, et al. Reduction in adjacent-segment degeneration after multilevel posterior lumbar interbody fusion with proximal DIAM implantation. J Neurosurg Spine. 2015;23(2):1-7.

26. Qu SD, Hai Y, Su QJ, Qu SP. Finite element analysis of the refined interspinous dynamic system based on Coflex. Zhongguo Zuzhi Gongcheng Yanjiu. 2015:19(22):3571-8.

27. Li AM, Li X, Yang Z. Decompression and coflex interlaminar stabilisation compared with conventional surgical procedures for lumbar spinal stenosis: a systematic review and meta-analysis. Int J Surg. 2017;40:60-7.

28. Yuan W, Su QJ, Liu T, et al. Evaluation of Coflex interspinous stabilization following decompression compared with decompression and posterior lumbar interbody fusion for the treatment of lumbar degenerative disease: a minimum 5-year follow-up study. J Clin Neurosci. 2017;35:24-9.

\section{Publisher's Note}

Springer Nature remains neutral with regard to jurisdictional claims in published maps and institutional affiliations.

Ready to submit your research? Choose BMC and benefit from:

- fast, convenient online submission

- thorough peer review by experienced researchers in your field

- rapid publication on acceptance

- support for research data, including large and complex data types

- gold Open Access which fosters wider collaboration and increased citations

- maximum visibility for your research: over $100 \mathrm{M}$ website views per year

At $\mathrm{BMC}$, research is always in progress.

Learn more biomedcentral.com/submissions 